\title{
IMPROVEMENT OF MACHINE SAFETY DEVICES
}

\author{
B. M. Hevko ${ }^{a}$, R. B. $\mathrm{Hevko}^{b}$, O. M. Klendi ${ }^{c, *}$, M. V. Buriak ${ }^{b}$, \\ Y. V. DZYADYKEVYCH ${ }^{b}$, R. I. ROZUM ${ }^{b}$ \\ a Ternopil Ivan Pul'uj National Technical University, Ruska Str., 56, Ternopil, Ukraine \\ ${ }^{b}$ Ternopil National Economical University, Lvivska Str., 11, Ternopil, Ukraine \\ ${ }^{c}$ Separated Subdivision of National University of Life and Environmental Sciences of Ukraine, Berezhany \\ Agrotechnical Institute, Akademichna Str., 20, Berezhany, Ukraine \\ * corresponding author: klendii_o@ukr.net
}

\begin{abstract}
The article presents a development of new machine safety devices, which provide protection of operating elements from overload. Theoretical calculations have been made in order to determine the optimum design, kinematic and dynamic parameters of safety devices. A test bench has been developed and experimental investigations have been conducted in order to determine basic parameters of overload clutches.
\end{abstract}

KEYWORDS: safety devices; overload clutch; design and kinematic parameters; dynamic load; test bench; operating elements of machines.

\section{INTRODUCTION}

Operating elements of the machines, which operate under a wide range of conditions with materials that have various flow characteristics, are most likely to come under influence of external loading, which is usually random and can be critical both for operating elements and their drives [1, 2, 4, 12, 16, 20]. Such critical loads often cause a breakdown of equipment, which requires significant material resources for its repair and a lengthy downtime, which has a negative influence on productivity and efficiency of technological machinery. That is why it is necessary to improve and develop advanced types of safety devices (overload clutches), choose their optimum design-kinematic parameters and operating modes when operating elements get overloaded, which can provide their reliable breakage protection, reduce dynamic load in the process of half coupling slipping and an automatic repair of machines after their overload is removed.

\section{MATERIALS AND METHODS}

In order to formalize the process of overload protection of machine operating elements, it is necessary to make calculations for determining the overload clutch parameters. This paper considers protection of operating elements of machines with rotating and axial as well as with only rotating process of operation. Figure 1 shows the design of a conveyer with an overload clutch.

While in operation, a loose material enters a body through a hopper and gets onto a screw feeder, which conveys it in the unloading direction. When solid bodies get into the space between the surface of the screw rotation and the inner surface of a screw body, there is a seizure and the screw stops [3]. In order to resume the operation of a screw conveyer, it has been

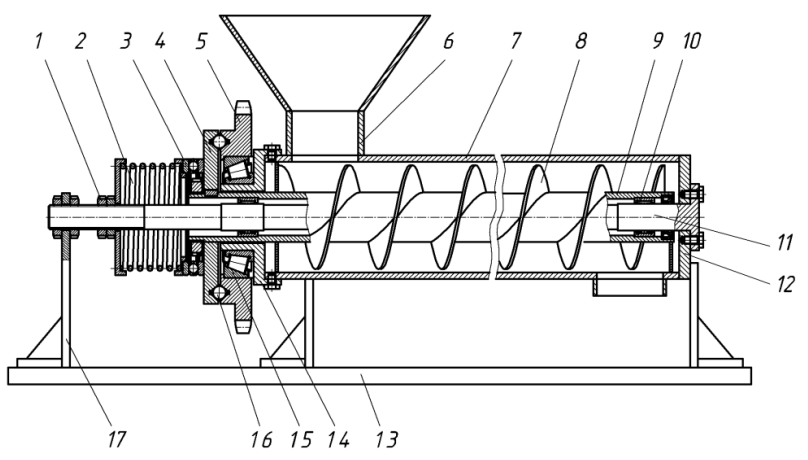

FiguRE 1. Screw conveyer with an overload clutch: 1 - nut; 2 - spring element; 3 - axial bearing; 4 -driven half coupling; 5 - drive half coupling; 6 - hopper; 7 screw body; 8 - screw feeder; 9 - pipe (screw feeder shaft); 10 - needle bearing; 11 - solid shaft; 12 - flange drive side; 13 - frame; 14 - flange non-drive side; 15 angular contact bearing; 16 - balls; 17 - rack.

suggested using an overload clutch with time-spaced slipping modes and an axial shift of a screw. Figure 2 represents its concept design and a general view of the work surface of a driven half coupling.

When the torque transmission takes place, balls contact the hollows of a drive half coupling, which provides the rotation of an overload clutch and a screw element. A driven half coupling is spline-mounted on a shaft with the possibility of an axial shift. A clearance, $\delta$, is provided between a driven half coupling and a nut; its value corresponds to a prevention mode. Diametrically to the arrangement of balls and hollows, on both sides of hollows on the driven half coupling's face, there are angled operational and reverse grooves; in this case, the operational groove angle $\beta$ is significantly less than the reverse groove angle $\gamma$. 

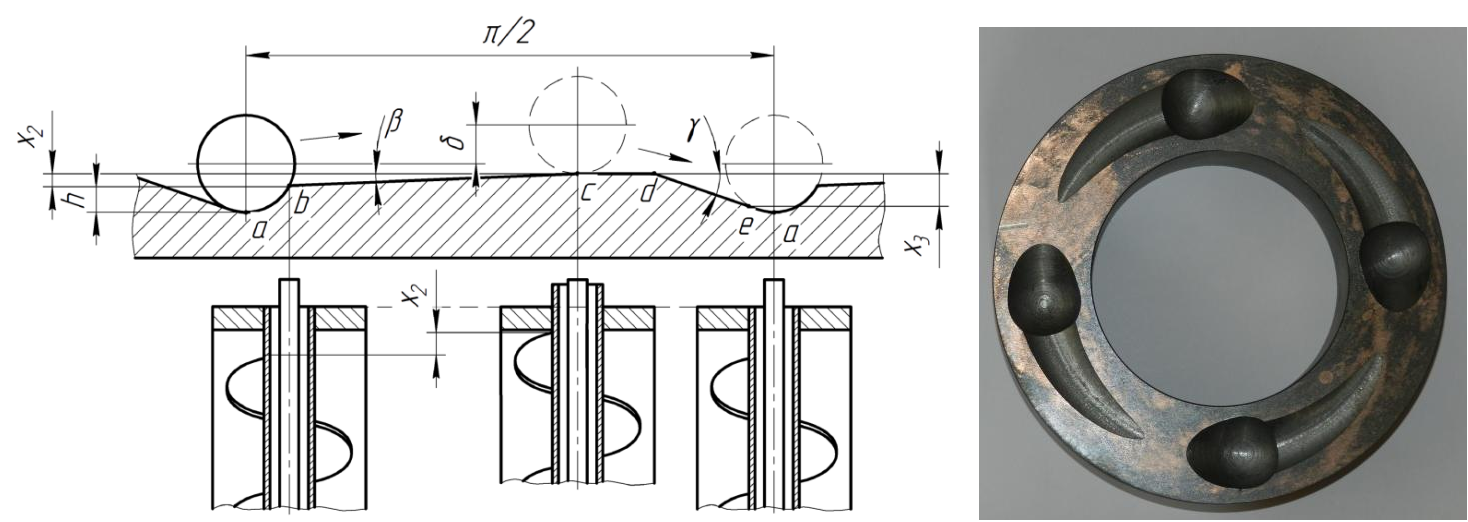

Figure 2. An overload clutch operation scheme.

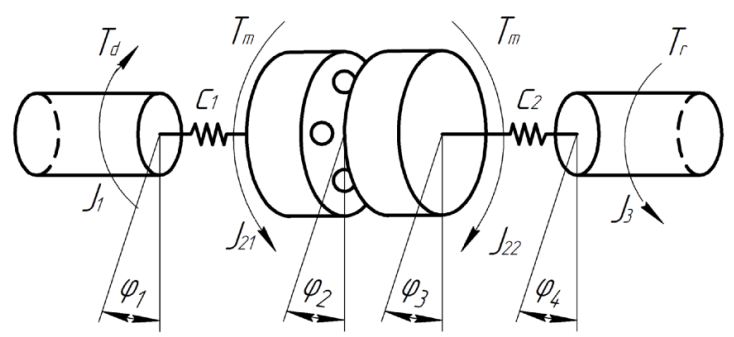

Figure 3. Dynamic model of an overload clutch with a screw operating element drive.

When there is an overload, the driven half coupling stops and the drive one continues to rotate, which causes a bond failure between the balls and hollows. Since the balls move along an operational groove, there is a 'soft' axial removal of a jammed screw. When there is a further rotation of a drive half coupling, the balls get into hollows along a reverse groove and thus the initial state of a clutch is restored.

In case of operating element seizure, there is major declutching of half couplings, that is to say, balls get out of hollows by value $h$ along $a b$-line, which causes disengagement of the kinematic chain of a drive. Then the balls move along the angled operational grooves (inclination angle $\beta$ ) of the driven half coupling (line bc) and thus there is a smooth 'soft' axial removal of the jammed screw operating element by the maximum value $x_{2}$, which significantly decreases dynamic load on a conveyer drive. As a result of a further rotation of a drive half coupling, the balls return to their initial state moving along angled reverse grooves (inclination angle $\gamma$ ) on the driven half coupling's face (line de) and a screw is moved by value $x_{3}$, resulting in a smooth restoration of the operational condition of the screw conveyer. Having conducted a kinetostatic analysis of an overload clutch operation in a screw conveyer, the pattern of the torque value change depending on the half coupling's rotation at various stages of their actuation has been determined [14].

In order to determine optimal parameters and characteristics of an overload clutch, its dynamic model with a screw operating element drive has been developed (Figure 3).

This model is described by the following set of equations:

$$
\begin{aligned}
J_{1} \ddot{\varphi}_{1} & =T_{\mathrm{d}}-c_{1}\left(\varphi_{1}-\varphi_{2}\right), \\
J_{21} \ddot{\varphi}_{2} & =c_{1}\left(\varphi_{1}-\varphi_{2}\right)-T, \\
J_{22} \ddot{\varphi}_{3} & =T_{\mathrm{m}}-c_{2}\left(\varphi_{3}-\varphi_{4}\right), \\
J_{3} \ddot{\varphi}_{4} & =c_{2}\left(\varphi_{3}-\varphi_{4}\right)-T_{\mathrm{r}},
\end{aligned}
$$

where $T_{\mathrm{d}}$ - rotating torque of a drive; $T_{\mathrm{m}}$ - rotating torque at half coupling's interaction; $T_{\mathrm{r}}$ - operating element shaft's resistive torque; $c_{1}$ - reduced torque stiffness of drive elements between an engine and a driven half coupling; $c_{2}$ - reduced torque stiffness of drive elements between a driven half coupling and an operating element shaft; $\varphi_{1}$ - angle of drive shaft's torque; $\varphi_{2}$ - angle of drive half coupling's torque; $\varphi_{3}$ - angle of driven half coupling's torque; $\varphi_{4}$ - angle of operating element shaft's torque; $J_{1}$ - equivalent drive moment of inertia; $J_{21}$ - equivalent drive half coupling's moment of inertia; $J_{22}$ - equivalent driven half coupling's moment of inertia; $J_{3}$ - equivalent operating element shaft's moment of inertia.

The rotating torque of half coupling's interaction $T_{\mathrm{m}}$ is determined according to many clutch parameters: the geometric dimensions of a half coupling and a profile of coupling elements; stiffness and initial contact spring tension; mass of axially moving part of a half coupling together with the screw and part of the load; influence of friction force (however, in case of proper lubrication, it is insignificant enough to not be taken into account).

It has been defined that torque dependence is determined by design, mass and spring characteristics of a clutch as well as the difference in angles of conjoint rotation of half couplings and their derivatives. Based on mathematical transformations, an expression for determining the rotating torque $T_{\mathrm{m}}$ has been obtained:

$$
T_{\mathrm{m}}=\frac{A+B+C+M}{E},
$$



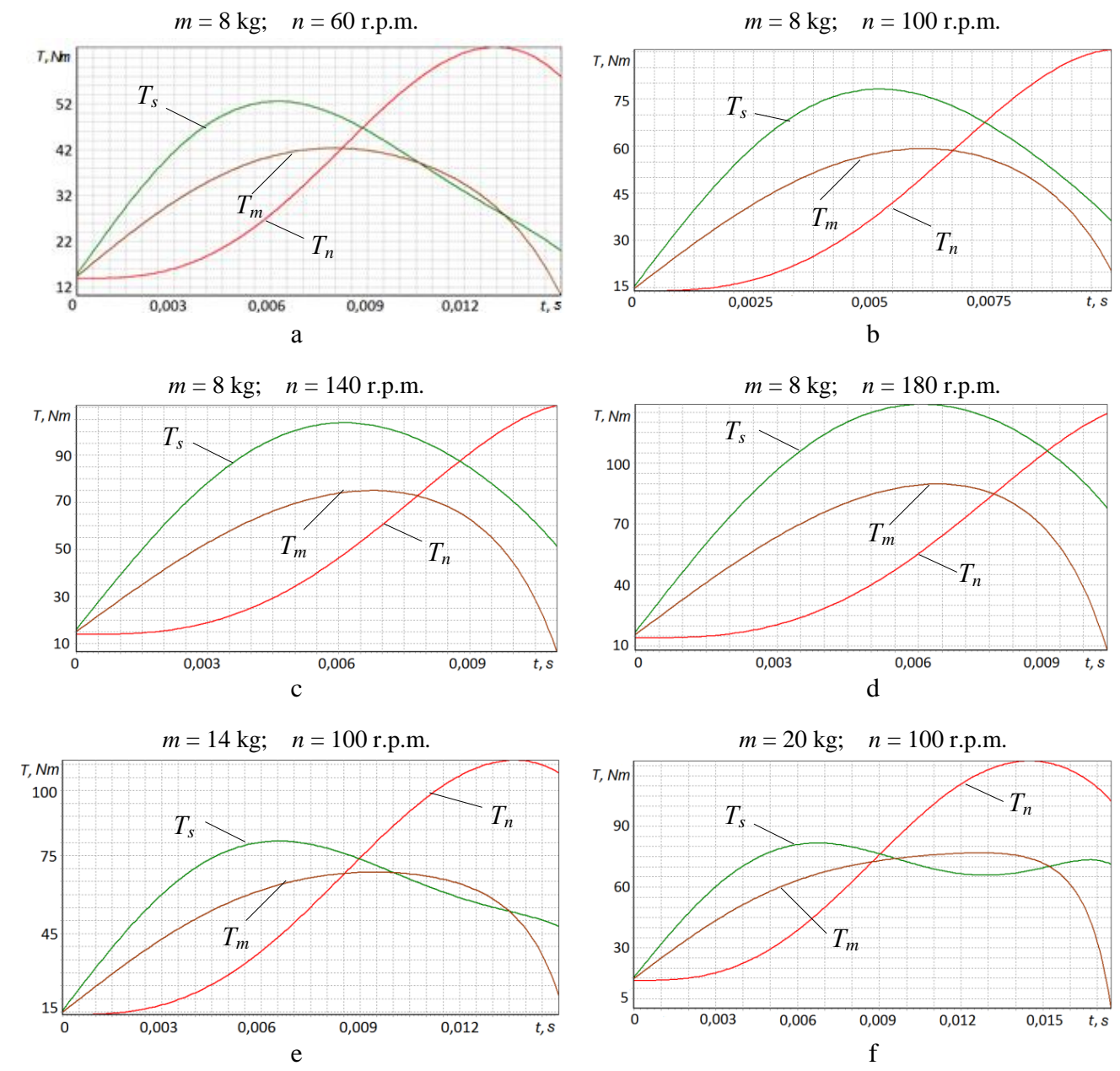

Figure 4. Torque-vs-half-coupling-rotation curves.

where components of the expression are written as

$$
\begin{gathered}
A=\frac{m(D / 2)^{2}\left(r \sin \theta_{0}-(D / 2)\left(\varphi_{2}-\varphi_{3}\right)\right)^{2}}{r^{2}-\left(r \sin \theta_{0}-(D / 2)\left(\varphi_{2}-\varphi_{3}\right)\right)^{2}} \\
\cdot\left(\frac{c_{1}\left(\varphi_{2}-\varphi_{3}\right)}{J_{21}}+\frac{c_{2}\left(\varphi_{2}-\varphi_{3}\right)}{J_{22}}\right), \quad(3) \\
B=\frac{m(D / 2)^{2}\left(\dot{\varphi}_{2}-\dot{\varphi}_{3}\right)^{2}\left(r \sin \theta_{0}-(D / 2)\left(\varphi_{2}-\varphi_{3}\right)\right)}{r^{2}-\left(r \sin \theta_{0}-(D / 2)\left(\varphi_{2}-\varphi_{3}\right)\right)^{2}}, \\
C=-\frac{m(D / 2)^{2}\left(\dot{\varphi}_{2}-\dot{\varphi}_{3}\right)^{2}\left(r \sin \theta_{0}-(D / 2)\left(\varphi_{2}-\varphi_{3}\right)\right)^{3}}{\left(r^{2}-\left(r \sin \theta_{0}-(D / 2)\left(\varphi_{2}-\varphi_{3}\right)\right)^{2}\right)^{2}}, \\
M=c(D / 2)\left(\lambda_{0}+h-r\right. \\
\left.+\sqrt{r^{2}-\left(r \sin \theta_{0}-(D / 2)\left(\varphi_{2}-\varphi_{3}\right)\right)^{2}}\right) \\
\cdot \frac{r \sin \theta_{0}-(D / 2)\left(\varphi_{2}-\varphi_{3}\right)}{\sqrt{r^{2}-\left(r \sin \theta_{0}-(D / 2)\left(\varphi_{2}-\varphi_{3}\right)\right)^{2}}}, \quad(6) \\
E=1+\frac{m(D / 2)^{2}\left(r \sin \theta_{0}-(D / 2)\left(\varphi_{2}-\varphi_{3}\right)\right)^{2}}{r^{2}-\left(r \sin \theta_{0}-(D / 2)\left(\varphi_{2}-\varphi_{3}\right)\right)^{2}} \\
J_{21} J_{22}
\end{gathered}
$$

where $D$ - diameter of the balls location on half couplings; $r$ - radius of the balls.
Figure 4 represents the torque-vs-half-couplingrotation curves. $T_{\mathrm{n}}=c_{1}\left(\varphi_{2}-\varphi_{1}\right)$ characterizes the rotating torque of a drive; $T_{\mathrm{S}}=c_{2} \varphi_{3}$ characterizes torque in case of a jammed driven half coupling and a screw operating element. During investigations, the following parameter values were set: $J_{1}=$ $40 \mathrm{~kg} \mathrm{~m}^{2} ; J_{21}=0.0157 \mathrm{~kg} \mathrm{~m}^{2} ; J_{22}=0.00925 \mathrm{~kg} \mathrm{~m}^{2}$; $c_{1}=c_{2}=1600 \mathrm{Nm} / \mathrm{rad} ; c=10000 \mathrm{~N} / \mathrm{m} ; h=4.6 \mathrm{~mm}$; $r=12 \mathrm{~mm} ; D=115 \mathrm{~mm} ; \delta_{0}=15 \mathrm{~mm}$. The rotation frequency of a screw operating element $n$ varied within the range of $60-180 \mathrm{rpm}$ and mass $m$ changed ranging from 8 to $20 \mathrm{~kg}$.

The results of the investigations show that an increase in rotation frequency $n$ causes an increase of rotating torques of the system. If the rotation frequency changes from 60 to $180 \mathrm{rpm}$, the rotating torque $T_{\mathrm{n}}$ is increased by $52.3 \%, T_{\mathrm{s}}$ is up by $59.8 \%$ and $T_{\mathrm{m}}$ is increased by $51.9 \%$. In addition, it has been determined that the mass increase of moving parts $m$ causes an increased drive load. If the mass is increased from 8 to $20 \mathrm{~kg}$, the rotating torque $T_{\mathrm{n}}$ is increased by $36.7 \%$, $T_{\mathrm{s}}$ by $15.6 \%$ and $T_{\mathrm{m}}$ by $34.5 \%$.

In order to reduce impact loads, which arise when the balls contact the hollows of the half couplings at their slipping, the following design of a ball-type over- 


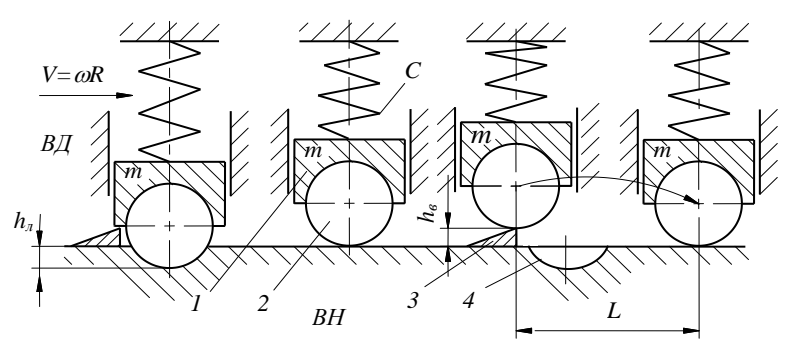

Figure 5. Roll-out process diagram of drive half coupling shift (DV) relative to a driven one (DVN).

load clutch has been suggested; its bearing elements are represented in Figure 5

When there is an overload of an operating element of a machine, a driven half coupling (DVN) slows down and stops. Here, a moving drive half coupling (DV) with a mass $m$ continues to rotate. This causes a disengagement of the coupling elements (in this case the balls get out of the hollows) and deformation of a spring with stiffness $C$, which axially presses a moving half coupling.

In typical overload clutches, when reaching the next hollows, the balls contact them and this causes circular impact loads on the drive elements [15. This disadvantage can be avoided if angled keys 3 , with a certain inclination angle $\beta$ and height $h_{\mathrm{k}}$, are arranged in front of the hollows 4 (Figure 5). Then, the balls 2 with a drive half coupling 1 , which moves at a rate $V=\omega R$ ( $\omega$ - angular velocity of a moving half coupling; $R$ - radius of a location of coupling elements) in the coupling area, get additional axial movement in the direction of the spring compression and under its action they get back in the opposite direction.

Such reciprocating movement takes certain time $t$, the time that a moving half coupling needs to cover the distance $L=\omega R t$, which exceeds the dimensions of a hollow. This eliminates the possibility of balls getting into hollows and reduces the level of circular impact loads.

Restoration of the initial state, at a constant resistive torque, is possible due to the reduction of the rotation frequency of a drive half coupling, which causes the decrease of the distance $L$ and reduces the contact between the balls and hollows.

The aim of conducting a dynamic analysis is the determination of overload clutch parameters at which a repeated contact of balls and the face of the driven half coupling, at a constant frequency of a driven half coupling, is possible only in the area between the hollows and angles keys.

Let us consider the movement of a half coupling together with a ball after its pullout from an angled key (Figure 6), which is performed in the process of a clutch actuation due to an overload. Let us assume that the angular velocity of a driven half coupling $\omega_{0}$ is constant and that of a driven one is equal to zero. When calculating, the following symbols were used: $\varrho$ - friction angle; $R$ - radius of the location of

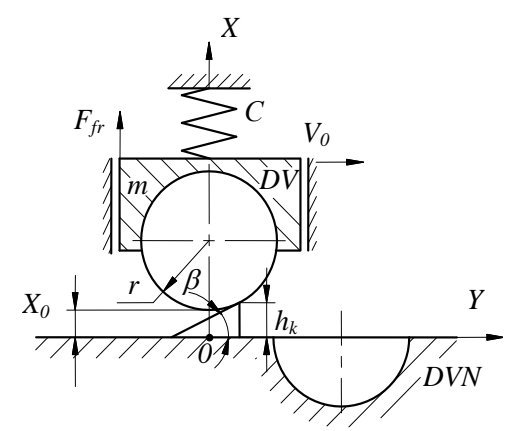

Figure 6. Analytical model of disengagement mechanism of half couplings

coupling elements; $h_{\mathrm{k}}$ - the height of an angled key; $\varphi$ - the angle of rotation of half couplings; $C$ - spring stiffness.

A half coupling is influenced by an elastic force, Coulomb friction, in the process of its free movement, after the balls lose contact with an angled key surface and until the moment of their contact with the face of the driven half coupling. Let us write the equation of the drive half coupling's motion at the moment of its separation from a key along $x$-axis, which is directly parallel to the axis of a drive shaft and is measured from the plane surface of a driven half coupling:

$$
m \ddot{x}=-C\left(x+\delta_{0}\right)-F_{\text {fr }} \operatorname{sgn} \dot{x} .
$$

Initial conditions of movement (at $t=0)$ :

$$
\begin{aligned}
& x(0)=h_{\mathrm{k}}-r(1-\cos \beta), \\
& \dot{x}(0)=V_{0} \operatorname{tg} \beta,
\end{aligned}
$$

where $V=\omega_{0} R$ - the linear speed of a moving half coupling and a ball relative to a stationary half coupling, transversely to $x$-axis.

Since there is a sign reversal $\operatorname{sgn} \dot{x}$ in the right member of the equation of the non-linear function, it is to the point to consider a solution of the equation, which consists of two parts: movement in the direction of the axis $(\dot{x}>0)$ and movement in the opposite direction $(\dot{x}<0)$. The solution of each equation is identical, but it differs by the sign of the friction force.

The first stage of the movement is described by

$$
m \ddot{x}=-C\left(x+\delta_{0}\right)-F_{\mathrm{fr}} ;
$$

after transformations it takes the following form:

$$
m \ddot{x}+C x=-C \delta_{0}-F_{\text {fr }} .
$$

In order to solve this differential equation, it is necessary to find relevant characteristic roots or $m k^{2}+C=$ 0 . Solution of the quadratic equation has complex roots

$$
k_{1,2}=i \sqrt{C / m},
$$

which indicates an oscillatory mode of the movement. 
A complete solution of (13), taking into account the partial solution, which depends on the right member, takes the following form:

$$
\begin{aligned}
& x=(A \sin \gamma t+B \cos \gamma t)-\lambda_{0}-F_{\mathrm{fr}} / C, \\
& \dot{x}=\gamma(A \cos \gamma t-B \sin \gamma t),
\end{aligned}
$$

where $\gamma=\sqrt{m / C}$.

Let us substitute the initial conditions and determine the constants of the integration

$$
\begin{aligned}
B & =h_{\mathrm{k}}-r(1-\cos \alpha)+\delta_{0}+F_{\mathrm{fr}} / C, \\
A & =\frac{V_{0} \operatorname{tg} \alpha}{\gamma} .
\end{aligned}
$$

The movement along $O X$-axis continues until the moving half coupling stops. Let's find the time $t_{1}$ of this stage of the movement by substituting $\dot{x}=0$ in (15):

$$
t_{1}=\frac{\operatorname{arctg} A / B}{\gamma} .
$$

During this time, the half coupling moves in the following position

$$
x_{1}=\left(A \sin \gamma t_{1}+B \cos \gamma t_{1}\right)-\delta_{0}-F_{\text {fr }} / C .
$$

The obtained value of the movement of the half coupling at the end of the first stage of the movement automatically becomes the initial condition of the movement for the second stage, which is described by the following equation with a positive sign of the friction force

$$
m \ddot{x}+C x=-C \delta_{0}+F_{\mathrm{fr}} .
$$

Respectively, its solution takes the following form

$$
\begin{aligned}
& x=(A \sin \gamma t+B \cos \gamma t)-\delta_{0}+F_{\text {fr }} / C, \\
& \dot{x}=\gamma(A \cos \gamma t-B \sin \gamma t),
\end{aligned}
$$

and constants of the integration are the following

$$
\begin{aligned}
& B=x_{1}+\delta_{0}-F_{\text {fr }} / C, \\
& A=0 .
\end{aligned}
$$

At the second stage, the movement finishes at the moment, when the ball of the moving half coupling contacts the face of the stationary coupling at $x=$ 0 . Let's substitute this value in (21) and we get a transcendent equation for calculating the time $t_{2}$ stage lasts that the second:

$$
\delta_{0}-F_{\text {fr }} / C=B \cos \gamma t_{2} .
$$

This can be solved with due accuracy only by applying a numerical method. In practice, in case of standard splined couplings, the following value can be taken as the first approximation:

$$
t_{2}=\frac{1}{\gamma} \arccos \frac{\delta_{0}-F_{\mathrm{fr}} / C}{B} .
$$

The total time of the contactless movement of the half couplings is

$$
t_{\mathrm{S}}=t_{1}+t_{2} \text {. }
$$

During this time, before its repeated contact with the driven half coupling's face, the drive half coupling moves in the direction of rotation by the following distance, relative to a key edge:

$$
L=V_{0} t_{\mathrm{S}}=\omega_{0} R t_{\mathrm{S}}
$$

The determined distance must be greater than the distance from an angled key to the furthest possible edge of an operating hollow, but it should not exceed the distance to the next angled key.

Based on the conducted calculations, it has been determined that the increase of a moving mass of a half coupling $m$ from 0.5 to $5 \mathrm{~kg}$ results in the increase of the contactless rotation of the half couplings from $L=7 \mathrm{~mm}$ to $L=43 \mathrm{~mm}$. An ascending angle $\beta$ of an angled key within the limits of $20^{\circ}$ to $70^{\circ}$ results in the linear increase of the value $L$ from 13 to $32 \mathrm{~mm}$. A further increase of $\beta$ for more than $70^{\circ}$ is inappropriate because there is the phenomenon of backward separation of a half coupling that results in an increased impact load and significant axial displacement of the half coupling.

In order to conduct experimental studies of overload clutches with radial-axial displacement of half couplings in screw conveyers (Figures 1 and 2), a test stand for determining their optimum parameters and operating modes has been developed and is presented in Figure 7

It consists of a frame 20 with a screw conveyer that contains a feed tube 7 , where there is a screw operating element 6 . On the entry side, where material is fed, $L$, $t_{\mathrm{s}}$ and $H_{\mathrm{max}}$, there is a hopper 5 and in the unloading area there is an opening with an adjustable shutter 9 and a screw shaft brake 8 . Drive of the operating element is provided by an electric motor 3 through an overload clutch 4 .

In order to provide the motor starting and to regulate its rotation frequency, a frequency converter (Altivar 71) with the software Power Suite v.2.5.0 was applied. Altivar 71 system was connected to the network and to a computer 1 .

The load can be set by a braking element as well as by using a sliding shutter. The results of the experimental studies of an overload clutch actuation in the form of a drive shaft rotation frequency curve, a torque curve and a power curve are shown on a computer display.

In order to reduce the dynamic load in the process of the relative half coupling's rotation when there is an overload, a low-dynamic fail-safe ball-type overload clutch has been developed and its design is shown in Figure 9

It consists of a drive half coupling 2 with balls 3 , which contact the hollows 4 of a driven half coupling 5 


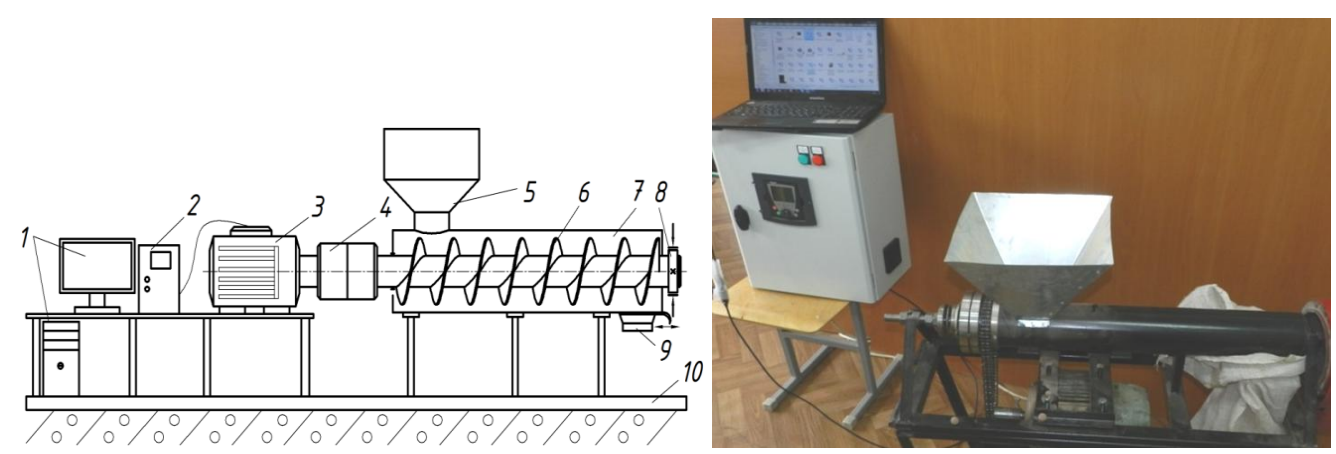

Figure 7. Design concept (left) and general view (right) of a test stand for investigating overload clutches: $1-$ computer; 2 - frequency converter Altivar 71; 3 - electric motor; 4 - overload clutch; 5 - hopper; 6 - screw; 7 - feed tube; 8 - screw shaft; 9 - shutter; 10 - frame.
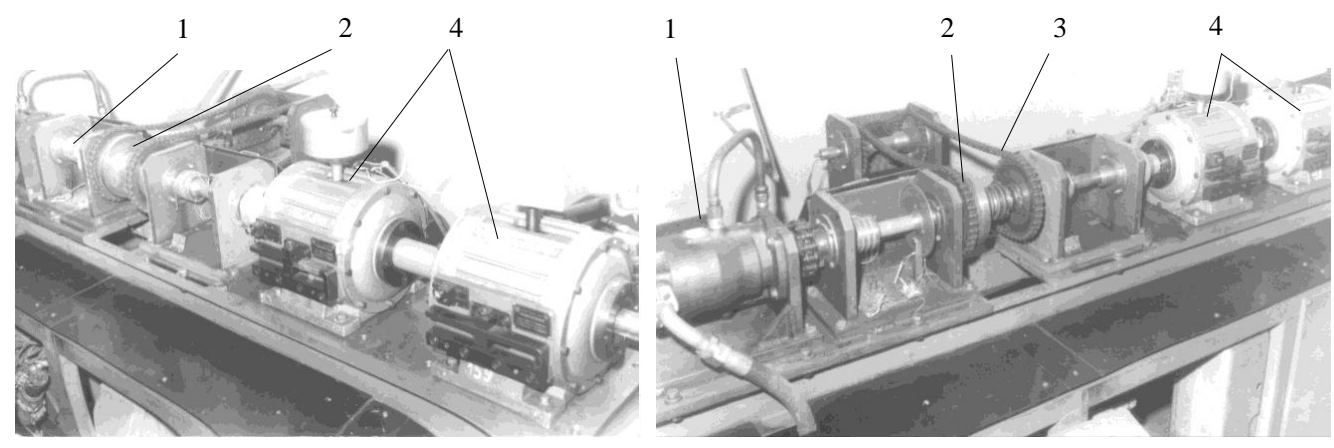

Figure 8. A test stand for investigating overload clutches
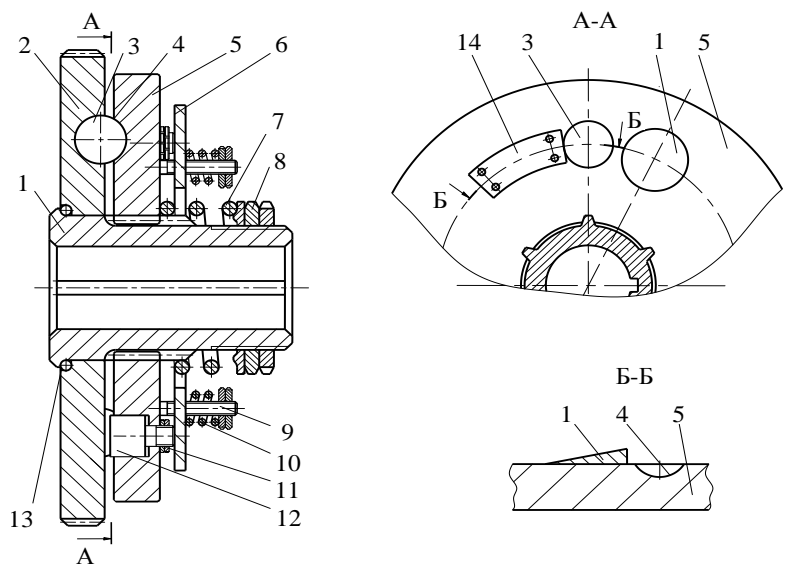

Figure 9. A fail-safe ball-type overload clutch.

on a hub 1. The driven half coupling is biased by a central spring 7 , which contacts nuts 8 . Diametrically to the arrangement of the balls and hollows, there are angled keys 14 and step pins 12. The end surface of step pins is displaced relative to the driven half coupling 5 and to the side of the drive half coupling 2 and step pins contact a pressure disk 6 on the other side.

There are adjustable limiting screws 11 arranged on the step pins on the side where they contact the pressure disk 6 . A pressure disk 6 is spring-biased to the side of the driven half coupling 5, the springs 10 are arranged on threaded axles 9 . In order to reduce the friction force between the face of the hub 1 and the drive half coupling 2, radial bearing balls 13 have been arranged.

When there is an overload, a hub decelerates and a driven half coupling decelerates as well. Here, the drive half coupling continues rotating and as a result, the balls loose contact with the hollows. Thus, in case when the torque increases over the limit, there is a complete uncoupling of the kinematic chain. When reaching the next hollows, balls move along grooves, which causes an additional axial shift of the driven half coupling and a spring deformation, respectively. Under a certain ratio of design and kinematic parameters of a clutch and its elements, the balls move over the hollows and hit the end face of the step pins (the pattern of motion is represented in Figure 5. This provides a dampening of the axial impact loads.

Motion trajectory of the balls excludes circular loads in the process of the clutch slipping and violent torque oscillation and decreases the hollow wear and reduces impact loads on a machine drive in general.

Restoration of the initial state of a clutch can be achieved by reducing its rotation frequency that makes the balls get into hollows, since there is a decrease in the distance relative to the contactless rotation of the half couplings until the balls contact the driven half coupling again.

In order to conduct the experimental research for investigating overload clutches with radial half couplings rotation, similar to the one represented in Figure 9, a test stand (Figure 8 for determining the quality of their operation has been developed. 

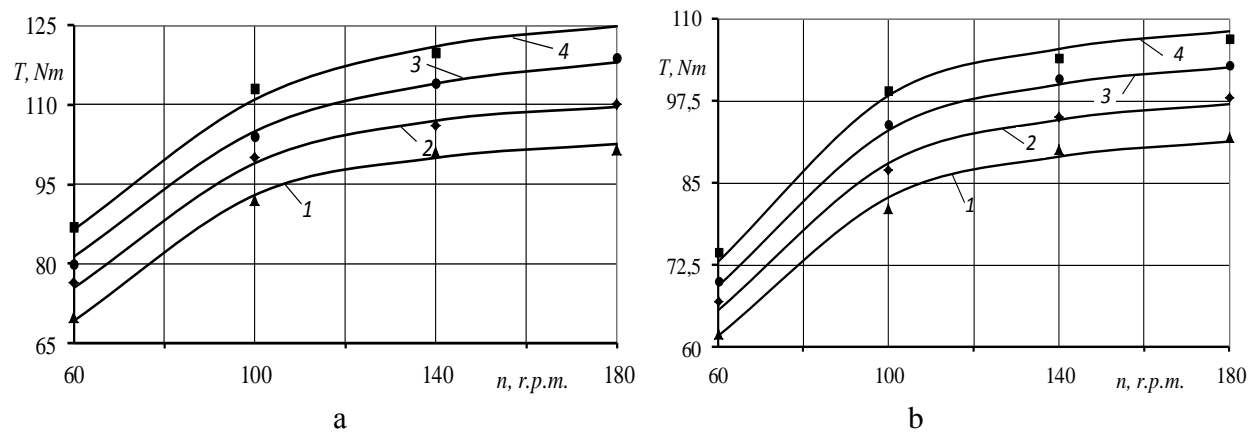

Figure 10. $T-n$ relation at different angles $\alpha$ of inclination (a) of an operating element to horizon: $1-\alpha=0^{\circ}, 2-$ $\alpha=10^{\circ}, 3-\alpha=20^{\circ}, 4-\alpha=30^{\circ}$; and spring stiffness (b): $1-c=6.5 \mathrm{~N} / \mathrm{mm}, 2-c=17.5 \mathrm{~N} / \mathrm{mm}, 3-c=18.5 \mathrm{~N} / \mathrm{mm}$, $4-c=19.5 \mathrm{~N} / \mathrm{mm}$.
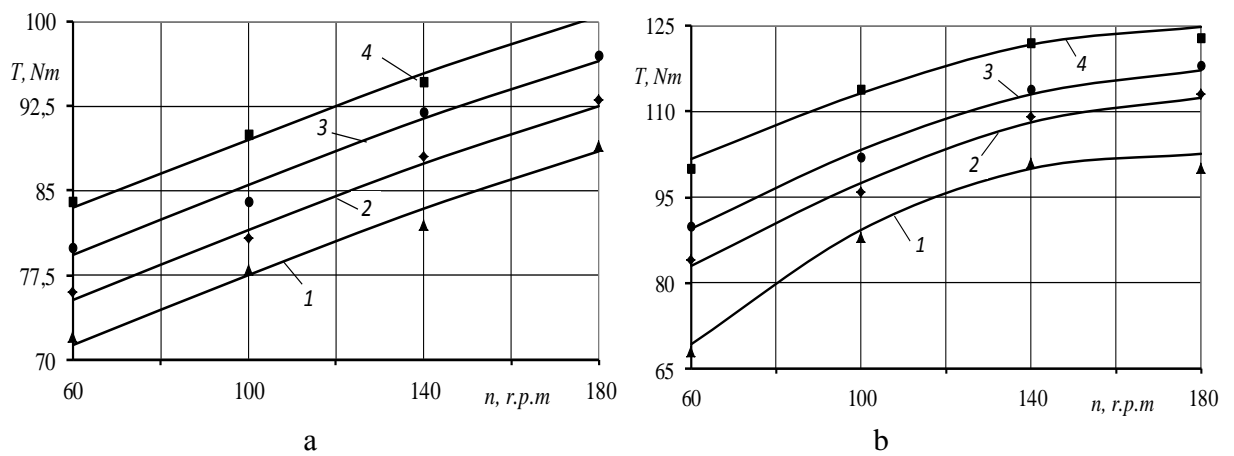

FiguRE 11. $T-n$ relation at different clearance settings (a): $1-\Delta=1 \mathrm{~mm}, 2-\Delta=1.5 \mathrm{~mm}, 3-\Delta=2 \mathrm{~mm}$; and at various materials (b): 1 - sand, 2 - wheat, 3 - corn, 4 - keramzit.

It consists of a hydraulic motor 1 that provides the rotation of an overload clutch 2 . With the help of a chain-drive 3 , a driven half coupling is connected with the take-off shaft of powder brakes 4 , which provide critical loads on an overload clutch.

\section{Results}

For investigating an overload clutch of a screw conveyer (Figures 1 and 2), experiments were set up for four frequencies of the operating element rotation, namely $n=60,100,140$ and $180 \mathrm{rpm}$. As a result of the conducted investigations, $T=f(n)$ were plotted (Figures 10 and 11). It has been determined that the torque increases with the increase in frequency of the rotation. In the variation range of $n=60-180 \mathrm{rpm}, T$ increases for $20-25 \%$. In addition, there is a tendency of a torque incensement $T$ relative to the change in the angle $\alpha$ of an inclination of an operating element to horizon, spring stiffness $c$ and clearance setting $\Delta$. Based on the conducted multi-factor experiment, a regression equation of the dependence of an overload clutch torque on the influence of single factors (the angle of inclination of an operating element to horizon $\alpha$, the frequency of operation element's rotation $n$ and the time of resistive torque increase $T_{\mathrm{o}}$ ) has been obtained:

$$
\begin{array}{r}
T=106.091-0.019 \alpha+0.142 \alpha n-0.012 n T_{0} \\
+0.062 T_{0}^{2} .
\end{array}
$$

When conducting the investigation, a factorial field was determined by the following range of parameter variation: $\alpha=0-40^{\circ} ; n=60-150 \mathrm{rpm} ; T_{\mathrm{o}}=0.2-0.7 \mathrm{~s}$.

Figure 12 represents response surfaces of torque $T$ relative to simultaneous change in two parameters: $T(n, \alpha) ; T\left(\alpha, T_{0}\right) ; T\left(n, T_{0}\right)$.

Their analysis shows that the dominating factor, which influences the value of $T$, is the frequency of operating element's rotation $n$, then, it is the angle of its inclination to horizon $\alpha$ and the least influential factor is the time of the resistive torque increase $T_{\mathrm{o}}$.

Based on the results of the investigation of a clutch with a radial half coupling rotation (Figure 9, which have been conducted using a test stand (Figure 8), regression equations have been obtained for determining a circular distance $L$ of the contactless half coupling's rotation after the coupling elements lose contact and until their repeated contact.

$$
L=-2.92+2.09 \omega+3.34 m-1.7 C .
$$

It has been determined that at the increase of $C$ from 5000 to $10000 \mathrm{~N} / \mathrm{m}$, the distance $L$ decreases by $12 \mathrm{~mm}(\Delta L=-12 \mathrm{~mm})$; at the change in $\omega$ from 13 to $27 \mathrm{rad} / \mathrm{s}: \Delta L=+19 \mathrm{~mm}$; at the increase of $m$ from 2 to $4.5 \mathrm{~kg}: \Delta L=+6 \mathrm{~mm}$; at the change in $\beta$ from 10 to $20^{\circ}: \Delta L=+3.5 \mathrm{~mm}$.

The quality coefficient of the clutch actuation (a loss in the torque value of the clutch actuation at the repeated uncoupling of half couplings) is about 


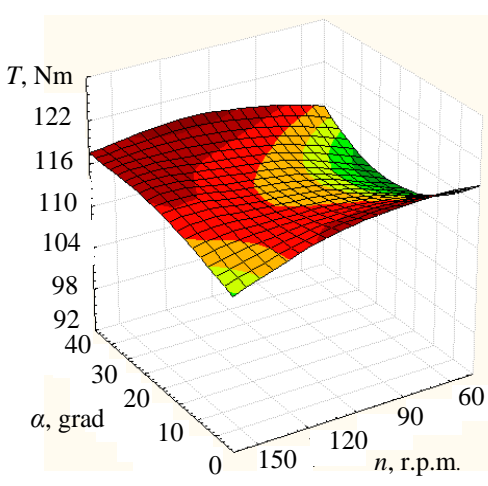

a

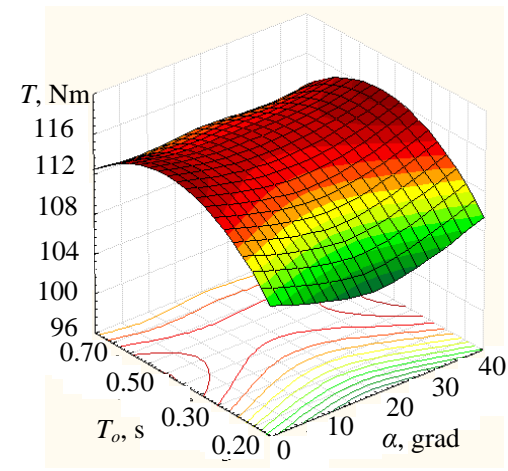

b

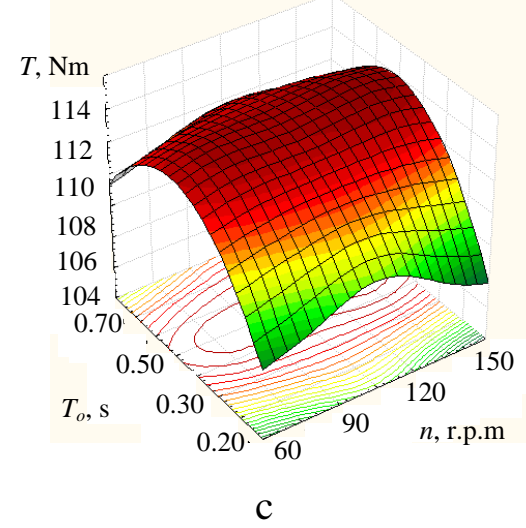

Figure 12. Response surfaces of torque $T$ relative to simultaneous change in two parameters: (a) $T=f(n, \alpha)$; (b) $T=f\left(\alpha, T_{\mathrm{o}}\right) ;(\mathrm{c}) T=f\left(n, T_{\mathrm{o}}\right)$.

$\gamma_{\mathrm{m}} \approx 1.25$. The stability factor of a clutch (the torque value of the clutch actuation after a certain time of its operation in relation to the initial one) is 0.945 at the integrated time of slipping being $600 \mathrm{~s}$ and torque rating $155-200 \mathrm{Nm}$.

\section{Conclusions}

The article presents theoretical and experimental investigations of two types of new designs of ball-type overload clutches: with a radial half coupling rotation and axial shift of a jammed screw in order to remove it from an overloaded area, and also a fail-safe ball-type overload clutch, which is to be mounted into the drives of technological machines, with reduced dynamic impact loads in the mode of a half coupling slipping.

Based on power, kinetostatic and dynamic analysis of the clutches, the pattern and the value of the torque change, at all stages of the relative rotation of half couplings, have been considered. The influence of the main parameters on the clutch actuation dynamics in case of the operating element's overload has been determined.

The developed research prototypes of the ball-type overload clutches and test equipment, involving the frequency converter Altivar 71 and software Power Suite v.2.5.0, made it possible to conduct complex experimental investigations. In case of an overload clutch of a screw conveyer, at an angle $\alpha$ varying from 0 to $30^{\circ}$, the torque $T$ increases by 39.7 (32.5\%); if the spring stiffness $c$ is increased from 16.5 to $19.5 \mathrm{~N} / \mathrm{mm}$, $T$ increases by $30.3(32.45 \%)$; at a clearance value $\Delta$ increase from 1 to $2.5 \mathrm{~mm}, T$ increases by 18.5 $(19.4 \%)$; if the material fraction is changed, the torque $T$ increases: in case of sand by $32.5 \%$; in case of wheat by $26.3 \%$; in case of corn by $23.6 \%$; and in case of keramzit by $18.5 \%$. Quality coefficient of the clutch actuation is within the range of $\gamma_{\mathrm{m}} \approx 1.25-1.27$ with the stability factor $0.938-0.945$ and with the integrated time of slipping being $600 \mathrm{~s}$ and the torque rating $155-200 \mathrm{Nm}$.

\section{REFERENCES}

[1] Hevko R.B., Klendiy M.B., Klendiy O.M. (2016) Investigation of a transfer branch of a flexible screw conveyer, INMATEH: Agricultural engineering, vol.48, no.1, pg.29-34.

[2] Hevko R.B., Rozum R.I., Klendiy O.M. (2016) Development of design and investigation of operation processes of loading pipes of screw conveyors, INMATEH: Agricultural engineering, vol.50, no.3, pg.89-94.

[3] Hevko R.B., Klendiy O.M., (2014), The investigation of the process of a screw conveyer safety device actuation, INMATEH: Agricultural Engineering, vol.42, no.1, pp.55-60, Bucharest/Romania.

[4] Lyashuk O.L., Rogatynska O.R., Serilko D.L. (2015) Modelling of the vertical screw conveyer loading, INMATEH. Agricultural Engineering. vol. 45, no 1, p. 87-94, Bucharest/Romania.

[5] Rogatynska O., Liashuk O., Peleshok T., Liubachivskyi R. (2015) - Investigation of the Proces of Loose Material Transportation by Means of Inclined Screw Conveyers, Bulletin of I.Pyliu Ternopil National Technical University, Vol.79, p. 137-143, Ternopil/Ukraine.

[6] Rohatynskyi R.M., Diachun A.I., Varian A.R. (2016) Investigation of Kinematics of Grain Material in a Screw Conveyor with a Rotating Casing. Bulletin of Kharkiv Petro Vasylenko National Technical Univarsity of Agriculture №168, p.24-31, Kharkiv.

[7] Kováčová, M., Matus, M., Krizan, P., Beniak, J.: Design theory for the pressing chamber in the solid biofuel production process, Acta Polytechnica, 54(1), 2014, p. 28-34. DOI:10.14311/AP.2014.54.0028

[8] Ebubekir Can Güneş, İsmet Çelik.: Use of disc springs in a pellet fuel machine, Czech Technical University in Prague, Acta Polytechnica, 57(2), 2017- p.89-96. DOI:10.14311/AP.2017.57.0089

[9] Loveikin V., Rogatynska O., Rogatynska L., Dudun Y., (2010), Dynamics of Screw Conveyers, Bulletin of I.Pyliui Ternopil National Technical University, Vol.15, pp.100-105, Ternopil/Ukraine.

[10] Loveikin V., Rogatynska L., (2011), A Model of Loose Material Transportation by Means of High-Speed Conveyers with Elastic Operating Devices. Bulletin of 
I.Pyliui Ternopil National Technical University, Vol.16, pp.66-70, Ternopil.

[11] Hevko R.B., Yazlyuk B.O., Liubin M.V., Tokarchuk O.A., Klendii O.M., Pankiv V.R. (2017), Feasibility study of the process of transportration and stirring of mixture in continuous-flow conveyers, INMATEH: Agricultural engineering, vol.51, no.1, pg.10-20, Bucharest/Romania.

[12] Qingang Xiong, Soroush Aramideh, Alberto Passalacqua and Song-Charng Kong (2015) Characterizing Effects of the Shape of Screw Conveyors in Gas-Solid Fluidized Beds Using Advanced Numerical Models, Journal of Heat Transfe, Vol. 137, Issue 6. DOI:10.1115/1.4029864

[13] Dziadykevych Y.V. and others, (2016), Environmental and Natural Resources Economics: monograph, Aston, p.392, Ternopil.

[14] Hevko R.B., Hlado Y.B., Shynkaryk M.I., Klendii O.M., (2014), Dynamic calculation of a safety device of screw conveyor, Bulletin of Engineering Academy of Ukraine, Vol.2, pp. 163-168.

[15] Hevko R.B., Buriak M.V., (2001), Ball safety clutch. Patent of Ukraine for invention No 40989A, IPC F 16D 7/06, No 2000127433. Bul. No 7, Ukraine, p.2.
[16] R.W. Nacheniusa, T.A. van de Wardta, F. Ronssea, W. Prinsa (2015) - Residence time distributions of coarse biomass particles in a screw conveyor reactor, Fuel Processing Technology, vol.130, pp. 87-95, Ghent, Belgium. DOI:10.1016/j.fuproc.2014.09.039

[17] P.J. Owen, P.W. Cleary (2009) - Prediction of screw conveyor performance using the Discrete Element Method (DEM), Powder Technology, Vol. 193, Issue 3, pp. 274-288, Clayton/ Australia. DOI:10.1016/j.powtec.2009.03.012

[18] D. Kretz, S. Callau-Monje, M. Hitschler, A. Hien, M. Raedle, J. Hesser. (2016) - Discrete element method (DEM) simulation and validation of a screw feeder system, Powder Technology, Vol.287, pp. 131-138, Mannheim / Germany. DOI:10.1016/j.powtec.2015.09.038

[19] A. S. Merritt, R. J. Mair (2015) - No Access Mechanics of tunnelling machine screw conveyors: model tests, Géotechnique, Vol. 56 Issue 9, pp. 605-615, Scotland. DOI:10.1680/geot.2006.56.9.605

[20] Philip J., Paul W. Cleary (2010) - Screw conveyor performance: comparison of discrete element modelling with laboratory experiments, Progress in Computational Fluid Dynamics, An International Journal (PCFD), Vol. 10, No. 5/6, 2010 Australia. DOI:10.1504/PCFD.2010.035366 